Document downloaded from:

http://hdl.handle.net/10251/50270

This paper must be cited as:

Gamero-Quijano, A.; Huerta, F.; Salinas Torres, D.; Morallón, E.; Montilla, F. (2014). Enhancement of the electrochemical performance of SWCNT dispersed in a Silica Sol-Gel matrix by reactive Insertion of a Conducting Polymer. Electrochimica Acta. 135:114-120. doi:10.1016/j.electacta.2014.04.172

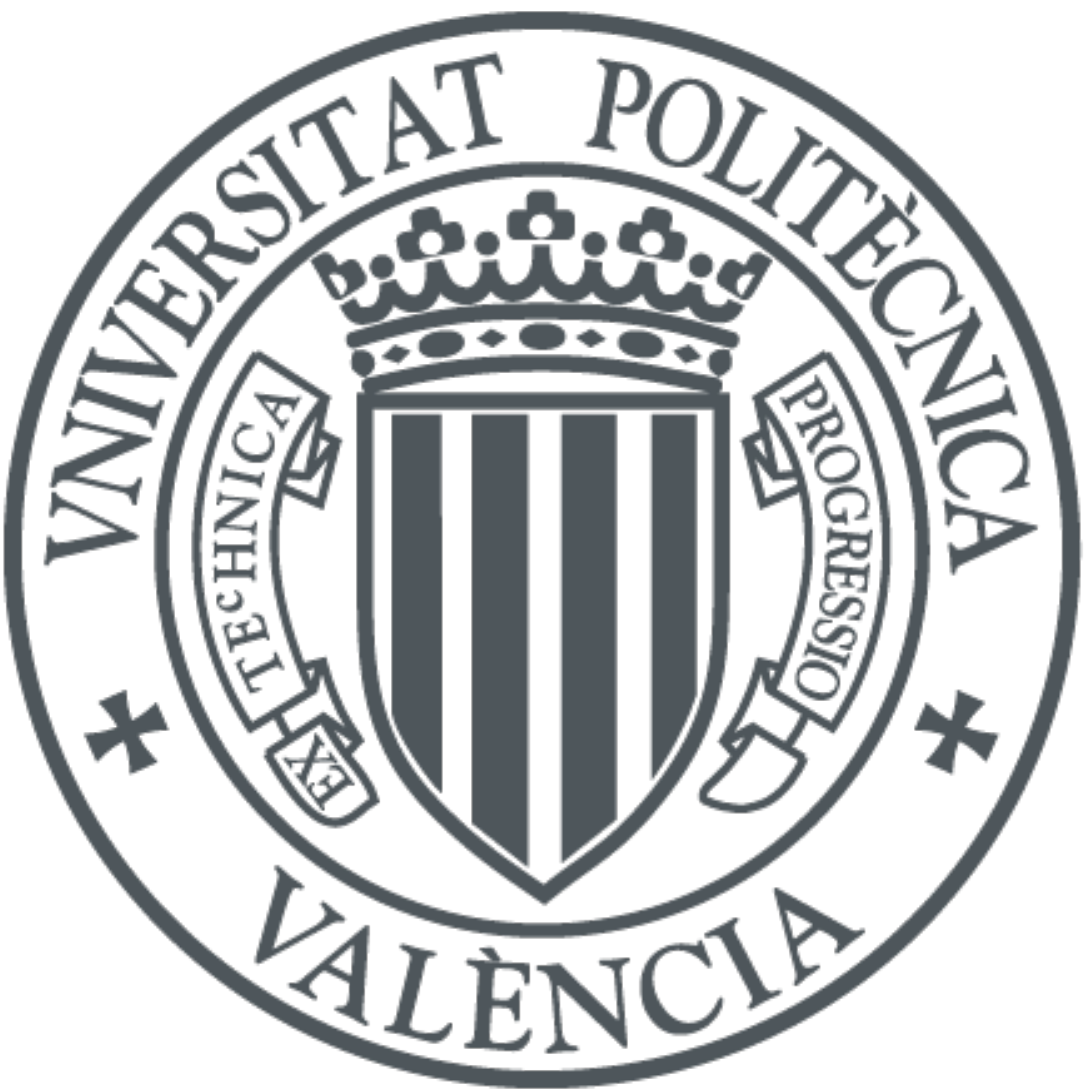

The final publication is available at

http://dx.doi.org/10.1016/j.electacta.2014.04.172

Copyright Elsevier

Additional Information 


\title{
Enhancement of the Electrochemical \\ Performance of SWCNT dispersed in a Silica \\ Sol-gel Matrix by Reactive Insertion of a \\ Conducting Polymer.
}

Alonso Gamero-Quijano ${ }^{1}$, Francisco Huerta ${ }^{2}$, David Salinas-Torres ${ }^{1}$, Emilia Morallón ${ }^{1}$, Francisco

Montilla ${ }^{1}$

${ }^{1}$ Dept. Química Física e Instituto Universitario de Materiales, Universidad de Alicante, Ap. 99, E-03080, Alicante, Spain

${ }^{2}$ Dept. Ingenieria Textil y Papelera, Universitat Politecnica de Valencia, Plaza Ferrandiz y Carbonell, 1. E-03801, Alcoy, Spain

\begin{abstract}
The electroassisted encapsulation of Single-Walled Carbon Nanotubes was performed into silica matrices $\left(\mathrm{SWCNT} @ \mathrm{SiO}_{2}\right)$. This material was used as the host for the potentiostatic growth of polyaniline (PANI) to yield a hybrid nanocomposite electrode, which was then characterized by both electrochemical and imaging techniques. The electrochemical properties of the SWCNT@SiO $2-\mathrm{PANI}$ composite material were tested against inorganic $\left(\mathrm{Fe}^{3+} / \mathrm{Fe}^{2+}\right)$ and organic (dopamine) redox probes. It was observed that the electron transfer constants for the electrochemical reactions increased significantly when a dispersion of either SWCNT or PANI was carried out inside of the $\mathrm{SiO}_{2}$ matrix. However, the best results were obtained when polyaniline was grown through the pores of the SWCNT@ $\mathrm{SiO}_{2}$ material. The enhanced reversibility of the redox reactions was ascribed to the synergy between the two electrocatalytic components (SWCNTs and PANI) of the composite material.
\end{abstract}

Keywords: PANI, SWCNT, Sol-gel silica, Hybrid nanocomposite 


\section{Introduction}

The use of sol-gel chemistry to prepare inorganic and organic-inorganic composite materials has become a matter of interest $[1,2]$. From the analytical point of view, the sol-gel process provides a relatively simple way to encapsulate chemical species in a stable host matrix like silica [3]. Besides, the versatility of the sol-gel chemistry offers many advantages for designing electrode devices and microscopic electrochemical reactors. Several synthetic routes for the production of sol-gel modified electrodes have been reported, including ways to produce surface and bulk modified electrodes, redox or electron conducting polymers, and their possible use in electrochemical sensing [2].

The sol-gel methodology applied to electrode surface modification is typically performed by coating the electrode with thin films obtained from a sol, which is obtained by the hydrolysis of metal alkoxyde precursors in water/alcohol solutions [4]. The production of sol-gel modified electrodes is usually performed by either spin coating or dip coating of the precursor solution on adequate supports.

An alternative method, which has been the focus of several studies, is the electrochemical or electro-assisted deposition method [5-9]. In particular, Shacham et al. applied the electrochemically assisted method for the deposition of titania thin films [10]. Electro-encapsulation within silica networks of several species, including conventional redox probes has been reported by Deepa et. al [11], who entrapped molecules such as basic blue 41 , methylene-blue, $\mathrm{Fe}(\mathrm{bpy}) 3^{2+}$ and $\mathrm{Ru}(\mathrm{bpy}) 3^{2}$. More recently Walcarius et. al [12] succeeded in the immobilization of redox active biomolecules such as glucose oxidase and hemoglobin.

However, from an electrochemical point of view, the use of silica networks in electrodes comes up against some difficulties, such as the lack of intrinsic electron 
conductivity. In order to overcome this problem, some chemical modifiers (namely, carbon nanomaterials, metal nanoparticles and conducting polymers) have been included in the inorganic matrix giving rise to hybrid silica materials [13-18]. The presence of this kind of modifiers yields enhanced electrocatalytic activity in addition to the improvement in electron conductivity.

Our research group has been recently interested in the use of electrochemistry to produce hybrid silica materials with no chemical gelification steps $[19,20]$. In particular, the electrocatalytic activity of Single-Walled Carbon Nanotubes dispersed within a $\mathrm{SiO}_{2}$ matrix was examined against several redox probes in a recent contribution [20]. It was reported in this study that the electroencapsulation of SWCNT gives rise to a well-dispersed SWCNT load within the silica film. The electrochemical performance of glassy carbon electrodes modified by $\mathrm{SWCNT} @ \mathrm{SiO}_{2}$ was tested against inorganic $\left(\mathrm{Fe}^{3+} / \mathrm{Fe}^{2+}\right)$ and organic (dopamine) redox probes. Both redox couples were chosen due to their different kinetic sensitivity to specific surface sites on carbon electrodes [21]. The iron redox couple is an oxide-sensitive probe, whose electrochemical behavior allows the quantification of the electroactive area related with the graphitic edges of SWCNT i.e., the nanotube tips [20, 22]. On the other hand, the dopamine organic probe reacts preferentially at the basal planes of the graphitic domains favored by $\pi-\pi$ interactions. In this way, the electron transfer takes place through the walls of the carbon nanotubes [22].

In our previous studies, the SWCNT@ $\mathrm{SiO}_{2}$ hybrid material showed a good electrochemical performance that improved the heterogeneous rate transfer for several redox probes [20]. However, this was followed by a minor increase in the electroactive area (the electrode area transferring the charge effectively). It was concluded that most SWCNTs remain isolated into the silica network and had not direct electrical connection 
with the supporting electrode. The goal of the present work is to improve the electrical contact of the dispersed carbon nanotubes by creating a conducting molecular wire between the SWCNT and the supporting electrode. For this purpose, we have grown polyaniline through the silica pores by reactive insertion $[19,23]$. The electrochemical performance of the new nanocomposite electrode, SWCNT@ $\mathrm{SiO}_{2}-\mathrm{PANI}$, was tested against either inorganic $\left(\mathrm{Fe}^{3+} / \mathrm{Fe}^{2+}\right)$ or organic (dopamine) redox probes and the morphology of the nanocomposite electrodes was characterized by electron microscopy.

\section{Experimental Part}

SWCNTs were purchased from Cheap Tubes Inc. (Brattleboro, VT, USA) with a purity of $95 \%$ and $1-2 \mathrm{~nm}$ of diameter. SWCNTs were used without further purification. Tetraethyl orthosilicate (TEOS) (Sigma-Aldrich), iron(II) sulfate heptahydrate (Merck, PA), iron(III) sulfate hydrate (Panreac, PA), potassium chloride (Merck, PA), dopamine (Sigma-Aldrich, PA), poly(4-styrenesulfonic acid) 18wt\% (PSS, Sigma-Aldrich), hydrochloric acid (Merck, PA), and sulfuric acid (Merck, PA) were also used as received. All solutions were prepared with purified water obtained from an ELGA LabWater Purelab system (18.2M $\Omega \mathrm{cm})$.

Electrochemical experiments were performed in conventional electrochemical glass cells. The working electrode was a glassy carbon bar (GC, V-25 model, Carbone Lorraine). The GC electrode was carefully polished with fine emery paper and alumina (Buehler, 1 and $0.5 \mu \mathrm{m}$ ) over cloth and then ultrasonically cleaned in distilled water. A platinum wire was employed as counter electrode, and a reversible hydrogen electrode introduced in the same electrolyte solution placed in a Luggin capillary was used as reference electrode. 
Cyclic voltammograms were performed with a potentiostat (eDAQ EA161) and a digital recorder (eDAQ, ED401) with eDAQ EChart data acquisition software. The current density was calculated from the geometric area of the electrode $\left(0.07 \mathrm{~cm}^{2}\right)$. The surface morphology of the electrodes was studied by scanning electron microscopy (SEM, JEOL JSM-840) and transmission electron microscopy (TEM, JEOL model JEM-2010). The scanning electron microscopy was performed directly on the glassy carbon working electrode. For transmission electron microscopy studies, the electrodeposited silica samples were carefully scratched from the surface of the glassy carbon electrode. This silica powder was dried by vacuum heating at $40^{\circ} \mathrm{C}$, subsequently dispersed with ethanol and dosed over the sample holder. Thermogravimetric analyses were carried out for the estimation of the amount of carbon nanotubes incorporated within the silica matrices. The silica samples were subjected to thermal treatment at $10{ }^{\circ} \mathrm{C} / \mathrm{min}$ up to 900 ${ }^{\circ} \mathrm{C}$ in $100 \mathrm{~mL} / \mathrm{min}$ of nitrogen/oxygen flow (ratio 4:1).

\subsection{Preparation of SWCNT@ $\mathrm{SiO}_{2}$ modified electrodes}

Carbon nanotubes were encapsulated into the $\mathrm{SiO}_{2}$ matrix simultaneously to its electrodeposition on glassy carbon electrodes. Initially, two solutions were prepared according to the following procedure:

Solution 1: Stable SWCNT aqueous suspensions were obtained as follows, $20 \mathrm{mg}$ of SWCNT were poured into a vial containing $20 \mathrm{ml}$ of $1 \%$ poly(4-styrenesulfonic acid) aqueous solution. The carbon nanotubes were dispersed and suspended by the applications of ultrasonic field by a VIRTIS probe (Virsonic 475, 475W maximum output power) at 1 minute intervals for $1 \mathrm{~h}$. To avoid overheating, samples were aircooled between sonication intervals. This suspension is stable for several months, due to the formation of SWCNT-PSS assemblies [24]. 
Solution 2: Silica solution was prepared through the alcohol-free sol-gel route [20, 2527]. $1.00 \mathrm{~mL}$ of TEOS was mixed under vigorous stirring with $2.52 \mathrm{~mL}$ of a $0.46 \mathrm{M}$ $\mathrm{KCl}+0.01 \mathrm{M} \mathrm{HCl}$ solution in a closed vessel. After 2 hours, the resulting sol was submitted to evaporation by vacuum heating until the complete removal of the released ethanol coming from alkoxyde hydrolysis.

For the modification of the electrodes $2.52 \mathrm{~mL}$ of solution 1 -SWCNT suspension- was poured into solution 2 -alcohol-free silica precursor-. The complete removal of ethanol from solution 2 is a key point, since the dispersion of SWCNT-PSS assemblies are unstable in the presence of alcohol.

This mixture containing SWCNT and the hydrolyzed silica precursor was placed in an electrochemical glass cell which contained a platinum wire counter electrode and a reversible hydrogen reference electrode.

The deposition of silica was performed potentiostatically by the immersion of a polished GC electrode in the precursor solution, pre-conditioned at a constant potential of $0.0 \mathrm{~V}$ and then stepped down to $-1.2 \mathrm{~V}$ for 60 seconds to trigger the deposition of the silica film. Hydrogen evolution upon electrochemical reduction of water at this potential leads to a $\mathrm{pH}$ rise in the electrode surroundings. This induces the collapse of silica colloids near the electrode surface and favors their deposition [19, 28]. During the collapse of silica colloids near the electrode surface, the suspended SWCNT are trapped to form SWCNT@SiO . Further details of the deposition method are given elsewhere $[19,20]$. The amount of carbon nanotubes incorporated into the electrodeposited silica matrices were determined to be around $4 \%$ by thermogravimetric analysis (see Fig. S1 in the Supporting Information). 


\section{Results and discussion}

\subsection{Electrochemical insertion of PANI into SWCNT@SiO ${ }_{2}$ modified electrodes}

A glassy carbon electrode modified with $\mathrm{SWCNT} @ \mathrm{SiO}_{2}$ was removed from the electrochemical cell and rinsed carefully with ultrapure water. Then, it was transferred to another cell containing a $0.5 \mathrm{M} \mathrm{H}_{2} \mathrm{SO}_{4}+0.1 \mathrm{M}$ aniline solution for the polymerization of PANI.

In order to facilitate the diffusion of aniline monomers within the silica pores, a potential of $0.0 \mathrm{~V}$ was applied for $60 \mathrm{~s}$. Then, it was applied a potential step up to +1.05 $\mathrm{V}$ to trigger the oxidation of aniline monomers. Fig. 1 shows the recorded chronoamperometric curve, where an initial sharp current can be observed due to the charge of the electrical double-layer.

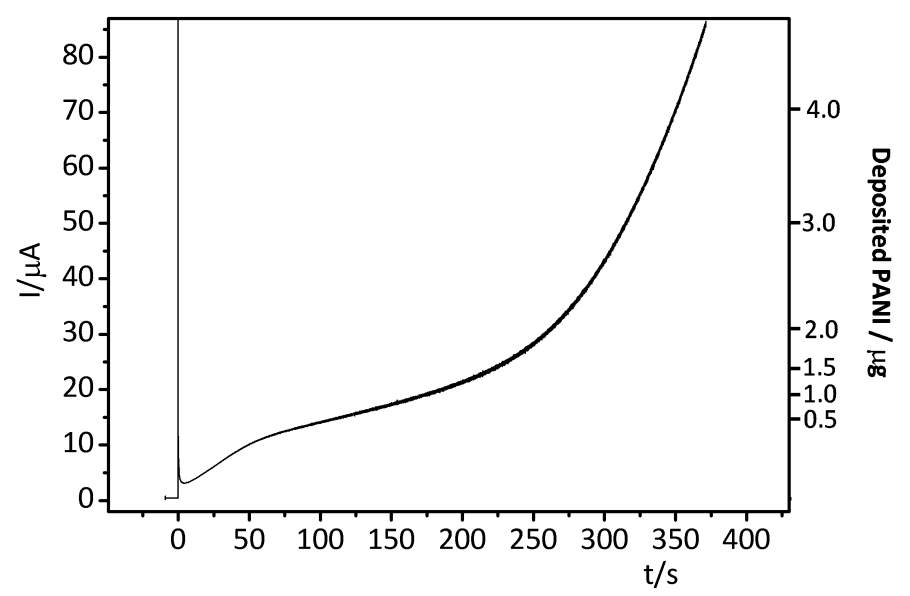

Figure 1. Potentiostatic growth of polyaniline within a SWCNT@ $\mathrm{SiO}_{2}$ modified electrode. Polymerization solution: $0.5 \mathrm{M} \mathrm{H}_{2} \mathrm{SO}_{4}+0.1 \mathrm{M}$ aniline hydrochloride. Initial potential: $+0.0 \mathrm{~V}$ vs RHE, final potential: $+1.05 \mathrm{~V}$ vs $\mathrm{RHE}$. 
After that process, the recorded current is due to the oxidation of aniline monomers to yield polyaniline. Two well-defined current regimes can be distinguished in the chronoamperogram. The first one is characterized by a curve with concave shape and comprises the time period between the start of the experiment and the inflection point at 148 s. After that time the chronoamperometric curve changes to a convex shape and the current follows an exponential dependence.

The shape of this curve resembles the chronoamperograms obtained in some of our previous papers $[19,23]$. The current recorded at times lower than the inflection point is related with the growth of PANI confined within the silica pores. On the contrary, the exponential region observed above $148 \mathrm{~s}$ is characteristic of the autocatalytic PANI growth. It is known that chronoamperometric curves showing exponential shape are recorded during aniline electropolymerization on bare electrode surfaces. Consequently, in Fig. 1 the characteristic shape reveals that the polymeric chain has eventually filled up the silica pores and is spreading out of this material $[19,23]$. The amount of polymer deposited in the composite material can be controlled by monitoring the oxidation charge and assuming 2 electrons per deposited monomer unit [29].

Scanning electron microscopy has been used to examine and compare the surface of SWCNT@SiO -PANI composite electrodes loaded with different amounts of polyaniline. Firstly, Fig. 2a shows a glassy carbon electrode modified with a deposit of $\mathrm{SiO}_{2}$ without nanotubes. It can be observed a very rough $\mathrm{SiO}_{2}$ layer which covers all the glassy carbon substrate and shows silica particles approaching the micrometer scale. 

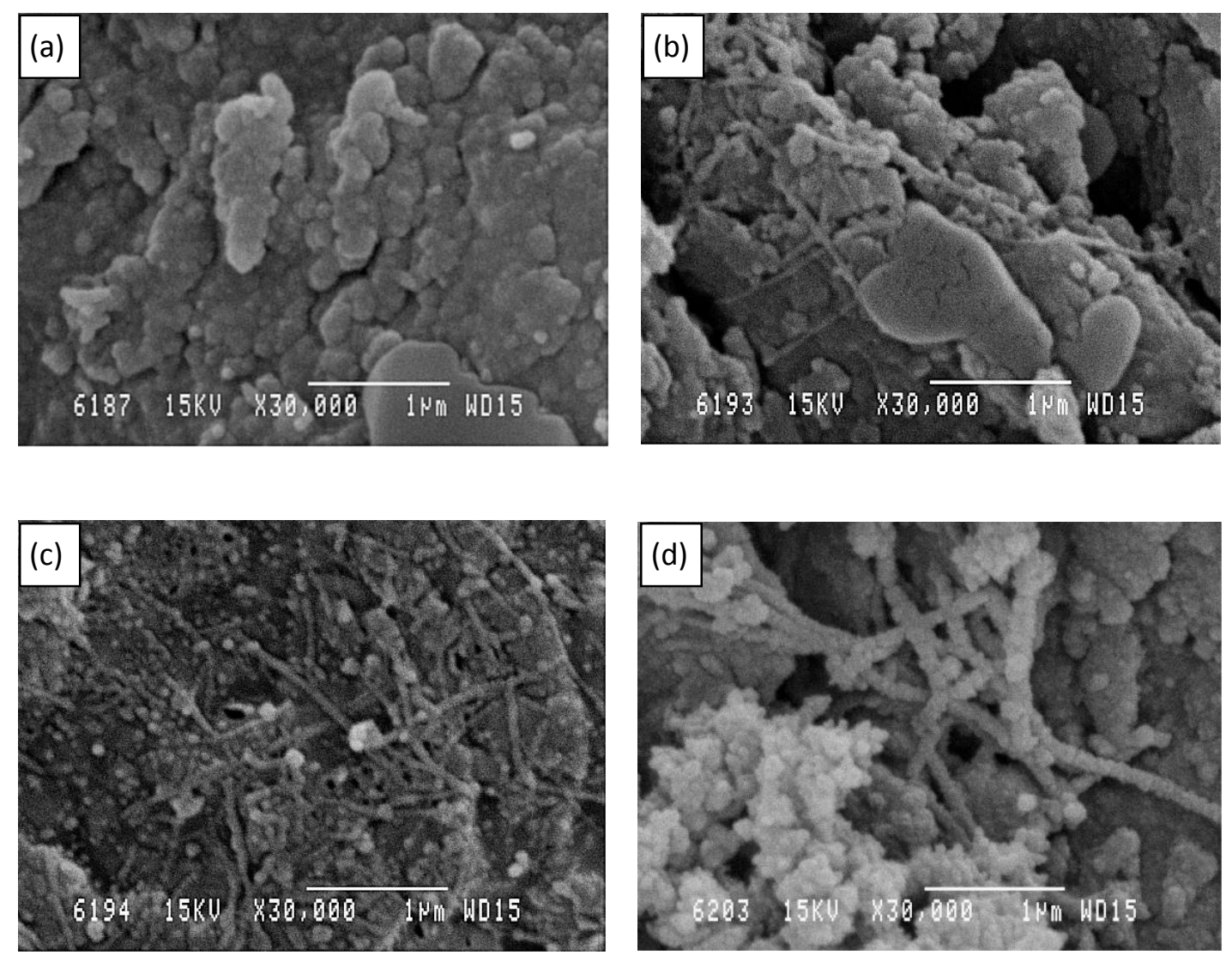

Figure 2. SEM micrographs acquired at the same magnification for glassy carbon substrates modified with (a) deposit of $\mathrm{SiO}_{2}$ and (b-d) $\mathrm{SWCNT} @ \mathrm{SiO}_{2}$ composite filled with polyaniline: (b) $0.472 \mu \mathrm{g}$, (c) $0.944 \mu \mathrm{g}$, (d) $4.72 \mu \mathrm{g}$.

On the other hand, Figs. $2 b$ to $2 d$ show different stages of polyaniline growth on the SWCNT@ $\mathrm{SiO}_{2}$ electrode. These stages correspond to polyaniline loads of $0.472 \mu \mathrm{g}$ (deposition time=106 s), $0.944 \mu \mathrm{g}$ (deposition time=165 s) and $4.72 \mu \mathrm{g}$ (deposition time $=370$ s) along the chronoamperometric curve shown in Fig. 1. The surface structure of the SWCNT@SiO 2 -PANI composite material loaded with $0.472 \mu \mathrm{g}$ polyaniline 
shows only some dispersed SWCNT bundles, since polyaniline growth is limited to the inner surface of the material and, therefore, is not visible in the outer zone of this electrode.

However, for a higher PANI load of $0.944 \mu \mathrm{g}$ (immediately after the inflection point in the chronoamperogram) some polymer chains have reached the outer surface of the silica layer. They appear in Fig. 2c as dispersed particles with diameters ranging from 50 to $100 \mathrm{~nm}$. These aggregates are similar in size to those obtained on a ITO-SiO 2 electrode modified with an electrochemically synthesized PANI layer [23].

Finally, when PANI was loaded at higher amounts (Fig. 2d), the formation of polymer aggregates surfacing from the silica pores can be more clearly observed. The carbon nanotube bundles on the surface appear thicker, indicating that PANI grew around them. It should be noted that PANI spreads over a space that already contained SWCNT and, consequently, an improvement of the connection between the carbon nanostructures is expected to occur.

TEM microscopy has been used to access the inner structure of the synthesized materials. Fig 3 shows TEM images obtained from a SWCNT@ $\mathrm{SiO}_{2}$ composite without PANI (Fig. 3a) and after the deposition of $4.72 \mu \mathrm{g}$ PANI (Fig. 3b-3d). The composite materials were scratched from the electrode surface and then deposited on the sample holder to acquire the TEM images. 

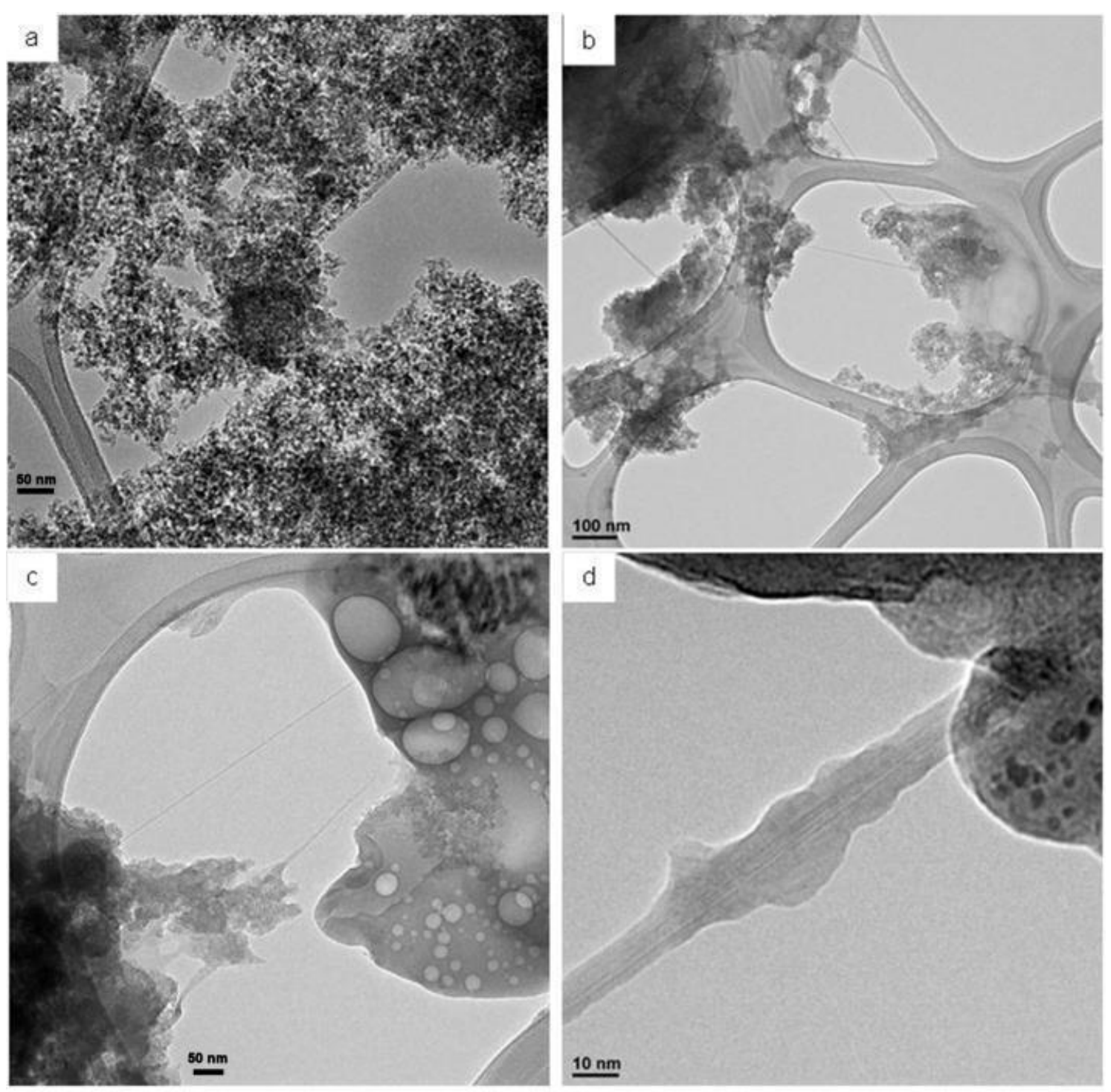

Figure 3. TEM micrographs obtained for (a) SWCNT@ $\mathrm{SiO}_{2}$ composite and (b-d) SWCNT@ $\mathrm{SiO}_{2}$ composite filled with $4.72 \mu \mathrm{g}$ of polyaniline at different magnifications.

The SWCNT@ $\mathrm{SiO}_{2}$ deposits in Fig. 3a present a globular and uniform aspect related to silica collapsed colloids. Some isolated carbon nanotubes appear in the borders of the silica island [20]. In addition to the globular silica deposits, Fig. 3b shows regions were electrogenerated PANI has grown. These regions can be observed in more detail in Fig. 
3c, where also several carbon nanotubes threads crossing the silica-PANI composite can be observed. A detailed view of one of these threads is shown in Fig. 3d, where the nanotube structures, of around $3 \mathrm{~nm}$ width, appear covered with PANI.

\subsection{Electrochemical characterization of SWCNT@SiO 2 -PANI composite electrodes}

SWCNT@SiO 2 -PANI modified electrode loaded with $0.944 \mu \mathrm{g}$ PANI was prepared to check its electrochemical performance. That PANI load was chosen because it corresponds to the complete filling up of the SWCNT@ $\mathrm{SiO}_{2}$ film. Fig. 4 shows the steady-state cyclic voltammogram recorded for this material in $0.5 \mathrm{M} \mathrm{H}_{2} \mathrm{SO}_{4}$.

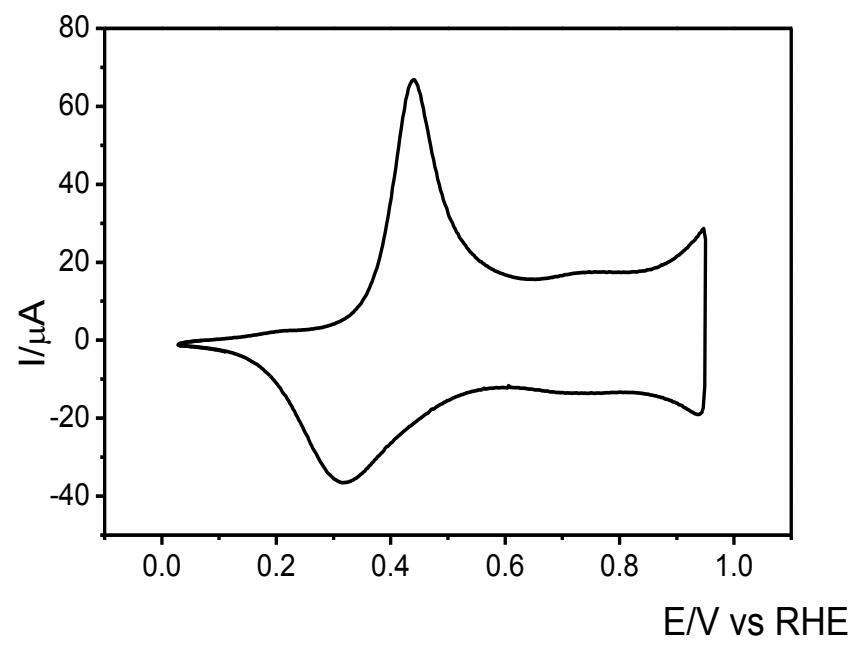

Figure 4. Steady-state cyclic voltammogram for a SWCNT@ $\mathrm{SiO}_{2}-\mathrm{PANI}$ modified glassy carbon electrode in $0.5 \mathrm{M} \mathrm{H}_{2} \mathrm{SO}_{4}$ supporting electrolyte. Scan rate: $50 \mathrm{mV} \mathrm{s}^{-1}$. 
During the forward potential scan, a sharp peak centered at $0.44 \mathrm{~V}$ appears in the $\mathrm{CV}$. This peak is related with the first redox transition of PANI from the leucoemeraldine (insulating) state to emeraldine (electronically conducting) state. On the other hand, the broad peak that can be hardly perceived at around $0.75 \mathrm{~V}$ has been usually ascribed to the presence of quinone-like defects in the structure of the conducting polymer [23, 30]. Finally, the current arising from $+0.9 \mathrm{~V}$ is due to the onset of the second redox transition of polyaniline from emeraldine to pernigraniline state. During the reverse scan, the corresponding reduction of emeraldine to leucoemeraldine occurs under the cathodic peak at $0.31 \mathrm{~V}$. In essence, the voltammetric profile described here is very similar to that obtained for conventional polyaniline layers deposited over smooth surfaces.

The modified electrode was tested against $\mathrm{Fe}(\mathrm{II}) / \mathrm{Fe}(\mathrm{III})$ and dopamine (DA) redox probes. It has been reported that the iron redox couple is a surface probe sensitive to the SWCNT tips whereas the dopamine redox couple is more sensitive to the nanotube walls. Accordingly, the use of these probes allows the characterization of both types of surface sites at the composite electrode.

The electrochemical response of the iron probe at different electrodes is exposed in Fig. 5. The dotted line shows the behavior of $\mathrm{Fe}^{2+} / \mathrm{Fe}^{3+}$ couple over the bare glassy carbon electrode. The broad anodic peak centered at $1.03 \mathrm{~V}$ appearing during the forward potential sweep is related with the iron(II) oxidation. During the reverse scan, the faradaic counter-process takes place and a reduction peak is recorded at $0.42 \mathrm{~V}$. These values yield a peak separation, $\Delta \mathrm{E}_{\mathrm{p}}=610 \mathrm{mV}$, which shows the poor electrochemical performance of this electrode towards the iron redox couple. 


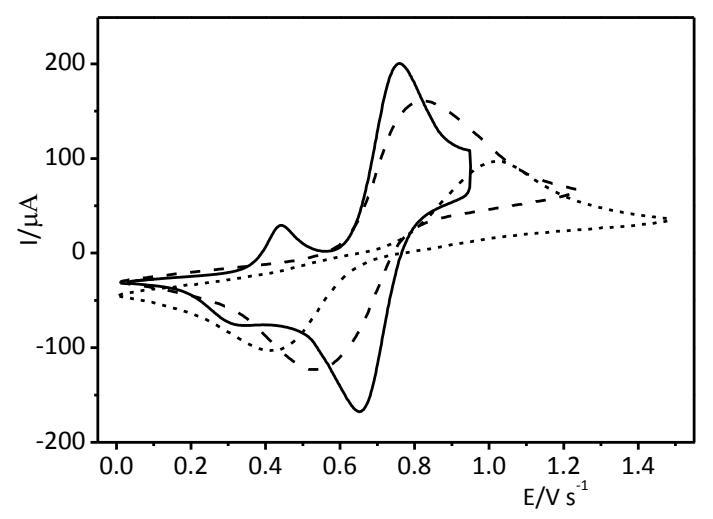

Figure 5. Electrochemical response of a bare glassy carbon electrode (dotted line); electrode modified with SWCNT@ $\mathrm{SiO}_{2}$ (dashed line) and SWCNT@ $\mathrm{SiO}_{2}-\mathrm{PANI}$ composite electrodes loaded with $0.944 \mu \mathrm{g}$ PANI (solid line) in $0.5 \mathrm{M} \mathrm{H}_{2} \mathrm{SO}_{4}+10 \mathrm{mM}$ $\mathrm{FeSO}_{4} / \mathrm{Fe}_{2}\left(\mathrm{SO}_{4}\right)_{3}$. Scan rate: $50 \mathrm{mV} \mathrm{s}^{-1}$.

When the electrode surface is modified with carbon nanotubes dispersed within the silica network (dashed line), the electrochemical reversibility of the $\mathrm{Fe}^{2+} / \mathrm{Fe}^{3+}$ redox couple improves considerably. The oxidation peak for iron (II) falls down to $0.82 \mathrm{~V}$ and the reduction peak for iron (III) shifts oppositely up to $0.52 \mathrm{~V}$. As a result, the peak to peak separation narrows to $300 \mathrm{mV}$ [20].

Finally, the response of SWCNT@ $\mathrm{SiO}_{2}$-PANI modified electrode appears as a solid line in the voltammograms. In this case, two anodic peaks appear during the forward scan. The first one, at $0.45 \mathrm{~V}$, is related with the leucoemeraldine-emeraldine transition of the inserted polyaniline and the second oxidation peak at around $0.75 \mathrm{~V}$ is related with the iron(II) oxidation. During the reverse scan, the reduction of iron (III) species appears at around $0.66 \mathrm{~V}$. So, the peak potential separation for this latter pair of peaks drops down 
to $107 \mathrm{mV}$. Table 1 summarizes these results for the $\mathrm{Fe}^{2+} / \mathrm{Fe}^{3+}$ redox reaction at the electrodes studied.

Table 1. Values for the voltammetric peak separation $\left(\Delta \mathrm{E}_{\mathrm{p}}\right)$ at $50 \mathrm{mV} \mathrm{s}^{-1}$, heterogeneous transfer rate constant $\left(k^{\circ}\right)$ and Electroactive Surface Area (ESA) obtained in either $10 \mathrm{mM} \mathrm{FeSO} / \mathrm{Fe}_{2}\left(\mathrm{SO}_{4}\right)_{3}$ or $1 \mathrm{mM}$ DA solutions for different electrodes.

\begin{tabular}{|c|c|c|c|c|c|c|}
\hline \multirow[t]{2}{*}{ Electrode } & \multicolumn{2}{|c|}{$\begin{array}{l}\Delta \mathbf{E}_{\mathbf{p}} \\
(\mathbf{m V})\end{array}$} & \multicolumn{2}{|c|}{$\begin{array}{c}k^{o} \\
\left(\mathrm{~cm} \mathrm{~s}^{-1}\right)\end{array}$} & \multicolumn{2}{|c|}{$\begin{array}{l}\mathrm{ESA} \\
\left(\mathrm{cm}^{2}\right)\end{array}$} \\
\hline & $\mathrm{Fe}^{3+} / \mathrm{Fe}^{2+}$ & DA & $\mathrm{Fe}^{3+} / \mathrm{Fe}^{2+}$ & $\mathbf{D A}$ & $\mathrm{Fe}^{3+} / \mathrm{Fe}^{2+}$ & DA \\
\hline GC & 610 & 350 & $1.06 \times 10^{-5}$ & $4.95 \times 10^{-6}$ & 0.0887 & 0.0429 \\
\hline SWCNT@SiO2 & 300 & 125 & $2.86 \times 10^{-4}$ & $3.61 \times 10^{-4}$ & 0.0964 & 0.0431 \\
\hline $\begin{array}{c}\text { SWCNT@SiO2- } \\
\text { PANI }\end{array}$ & 107 & 60 & $3.50 \times 10^{-3}$ & $2.04 \times 10^{-3}$ & 0.153 & 0.233 \\
\hline $\mathrm{SiO}_{2}$-PANI & 141 & 79 & $1.81 \times 10^{-3}$ & $1.08 \times 10^{-3}$ & 0.154 & 0.164 \\
\hline
\end{tabular}

At this point, it is worth considering the possibility that inserted polyaniline could contribute to the improvement of the electrochemical reversibility of the iron redox reaction. To check this, a new experiment was performed in which polyaniline was grown through the pores of a $\mathrm{SiO}_{2}$ layer without SWCNT. When this material was used 
as electrode for the $\mathrm{Fe}^{2+} / \mathrm{Fe}^{3+}$ reaction, it was found a peak to peak separation close to $141 \mathrm{mV}$ (the voltammogram is shown in the Supporting Information, Fig. S2). Such a value falls between those for SWCNT@SiO 2 and SWCNT@ $\mathrm{SiO}_{2}-\mathrm{PANI}$. So, the electrode containing both carbon nanotubes and polyaniline shows better electrochemical reversibility. It seems that there exists a synergistic effect of SWCNT and polyaniline on the redox behavior of $\mathrm{Fe}^{2+} / \mathrm{Fe}^{3+}$.

The electrochemical response of these electrodes was also tested against the dopamine redox probe as shown in Fig. 6.

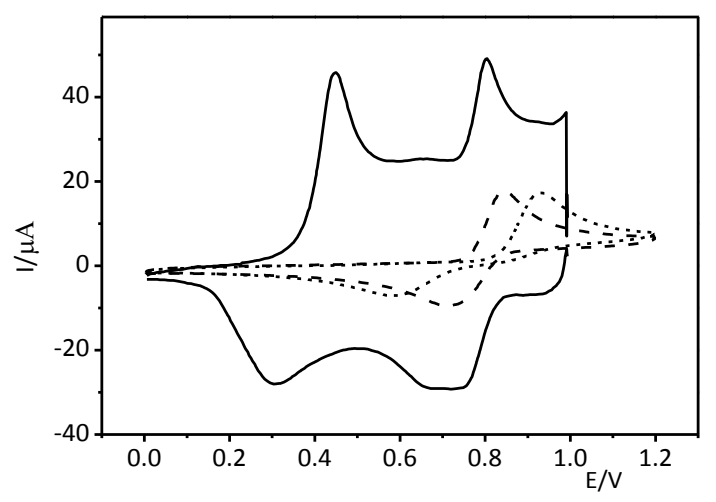

Figure 6. Electrochemical response of a bare glassy carbon electrode (dotted line); electrode modified with SWCNT@ $\mathrm{SiO}_{2}$ (dashed line) and SWCNT@ $\mathrm{SiO}_{2}-\mathrm{PANI}$ composite electrodes loaded with $0.944 \mu \mathrm{g}$ PANI (solid line) in $0.5 \mathrm{M} \mathrm{H}_{2} \mathrm{SO}_{4}+1 \mathrm{mM}$ dopamine. Scan rate: $50 \mathrm{mV} \mathrm{s}^{-1}$. 
Steady-state cyclic voltammograms were recorded for GC (dotted line) SWCNT@ $\mathrm{SiO}_{2}$ (dashed line) and SWCNT@ $\mathrm{SiO}_{2}-\mathrm{PANI}$ (solid line) in $0.5 \mathrm{M} \mathrm{H}_{2} \mathrm{SO}_{4}+1 \mathrm{mM}$ dopamine solution. It is clearly derived from these voltammetric curves that the improvement in electrochemical reversibility for DA redox reaction follows a similar pattern to that of $\mathrm{Fe}^{2+} / \mathrm{Fe}^{3+}$. Table 1 shows the peak to peak separation for the glassy carbon electrode, $350 \mathrm{mV}$. Such a value decreases to $125 \mathrm{mV}$ when the electrodes are modified with carbon nanotubes dispersed within the silica matrix. The best electrochemical response is found for the silica deposit modified with both PANI and SWCNT. In that case the measured $\Delta \mathrm{E}_{\mathrm{p}}$ is as low as $60 \mathrm{mV}$.

The contribution of polyaniline to the improvement of the electrochemical reversibility of this redox reaction was determined by checking the response of an electrode modified with hollow $\mathrm{SiO}_{2}$ (with no nanotubes inserted) and polyaniline grown through its pores. In this case, the peak separation is $79 \mathrm{mV}$ (the voltammogram is shown in the Supporting Information, Fig. S3). All these results confirm a clear synergistic effect between carbon nanotubes and PANI.

From $\Delta \mathrm{E}_{\mathrm{p}}$ data shown in Table 1 , standard rate constants for the electron transfer, $k^{o}$, have been calculated according to the Nicholson method [31]. The obtained parameters for each redox reaction and modified electrode are summarized in Table 1. Regarding the standard rate constants $\left(k^{\circ}\right)$ it can be observed that the GC electrodes show the lowest figures for both redox probes. An improvement of this parameter was achieved after the modification with carbon nanotubes-silica matrices. However, the best result is attained for the silica network that contains SWCNT connected by conducting polyaniline, with an improvement of the rate constant higher than 2 orders of magnitude for each redox probe. The $k^{o}$ values obtained for SWCNT@ $\mathrm{SiO}_{2}-\mathrm{PANI}$ modified electrodes are in the order of $10^{-3} \mathrm{~cm} \mathrm{~s}^{-1}$ for both redox probes. These values are similar 
to those obtained after the modification of GC electrodes with SWCNT prepared by drop-casting [22]. The major advantage of the method presented in this work is the lower amount of electrocatalytic material (SWCNT) used, which is 20 times lower than in that previous work.

Also the Electroactive Surface Area (ESA) of the electrode materials, i.e. the real area transferring charge to redox probes, has been evaluated. This has been done from Randles-Sevcik plots of peak current vs the square root of the scan rate (see Fig. S4 and S5 in the Supporting Information). The linear trends show that the electron transfer takes place from the modified electrode surface to dissolved species in all cases.

Significant differences in the electroactive area can be found in Table 1 between the two redox probes studied. For the GC electrode the $\mathrm{Fe}^{2+} / \mathrm{Fe}^{3+}$ reaction occurs at an effective electrode area close to $0.09 \mathrm{~cm}^{2}$. This value slightly increases when the transfer takes place at $\mathrm{SiO}_{2}$ filled with SWCNT, but almost doubles when polyaniline is added to the composite electrode. The presence of carbon nanotubes has little effect in this parameter and the ESA measured is similar for SWCNT@SiO $2-\mathrm{PANI}$ or $\mathrm{SiO}_{2}-\mathrm{PANI}$ modified electrodes $\left(0.15 \mathrm{~cm}^{2}\right)$. To interpret correctly this result, it should be noted that the surface sites for the electron transfer from iron ions are located at both the oxidized tips of SWCNT and the inserted PANI chains. Since the active area of the SWCNT tips is as low as $0.4 \%$ of their geometric area for this particular probe [19], the addition of polyaniline to the electrode material will dominate the final number of active sites. As a result, those electrodes filled with PANI show almost the same electroactive area for the $\mathrm{Fe}^{2+} / \mathrm{Fe}^{3+}$ redox reaction. The effect of SWCNT is then restricted to an improvement of the electrode kinetics by means of $k^{o}$. 
More important effects, in terms of changes in ESA, are due to carbon nanotubes are expected for dopamine redox probe, since it is known that the electron transfer for this organic compound occurs at the walls of SWCNT [19]. From the Randles-Sevcik slope, the electroactive surface area was calculated for this redox probe and the values are shown in the last column in Table 1. For the dopamine reaction taking place on either bare glassy carbon or SWCNT@ $\mathrm{SiO}_{2}$ modified electrodes, the area remains as low as $0.04 \mathrm{~cm}^{2}$. A significant improvement of this figure is obtained after electrode modification with PANI but the best result in terms of ESA is obtained in the presence of carbon nanotubes. The electrode modified only with PANI shows an area of 0.16 $\mathrm{cm}^{2}$, which is similar to that for the iron redox probe. However the electrode modified with carbon nanotubes and PANI shows an area of $0.23 \mathrm{~cm}^{2}$, a value five times higher for the same reaction than the area of a SWCNT@ $\mathrm{SiO}_{2}$ modified electrode. This result strongly suggests that PANI serves as a conducting connector for the carbon nanotubes dispersed in the silica matrix.

\section{Conclusions}

The present contribution shows the electrochemical synthesis of porous composite electrodes prepared on glassy carbon substrates and made of silica, single walled carbon nanotubes and polyaniline. The imaging techniques reveal a good dispersion of SWCNT within the porous layer of $\mathrm{SiO}_{2}$ and the successful coating of these structures by the potentiostatically inserted polyaniline.

The electrochemical properties of the SWCNT@SiO 2 -PANI composite material were tested against either inorganic $\left(\mathrm{Fe}^{3+} / \mathrm{Fe}^{2+}\right)$ or organic (dopamine) redox probes. Thanks to its porous structure, the silica layer allows the permeation of the redox probes to the 
inner material. Consequently, the electron transfer takes place inside of the nanocomposite electrode to species in solution, a point that is confirmed by the kinetic analysis.

The electrochemical reversibility of these redox probes at a glassy carbon electrode is rather poor. The electron transfer constants for the electrochemical reactions increased significantly when a dispersion of either SWCNT or PANI was carried out inside of the $\mathrm{SiO}_{2}$ matrix. However, the best results were obtained when polyaniline was grown through the pores of the SWCNT@ $\mathrm{SiO}_{2}$ material. It was concluded that the improved electrochemical reversibility was due to synergistic effects between the electrocatalytic components of the composite.

\section{Acknowledgements}

This work was financed by the following research projects: MAT2010-15273 of the Spanish Ministerio de Economia y Competitividad and CIVP16A1821 of the Fundación Ramón Areces and PROMETEO 2013/038 of the Generalitat Valenciana. Alonso Gamero-Quijano is grateful to Generalitat Valenciana (Santiago Grisolia Program) for the funding of his research fellowship. David Salinas-Torres is grateful to Ministerio de Economia y Competitividad for the funding of his research fellowship. 


\section{References}

1. A. Walcarius, Chem. Mater., 13 (2001) 3351.

2. O. Lev, Z. Wu, S. Bharathi, V. Glezer, A. Modestov, J. Gun, L. Rabinovich, S. Sampath, Chem. Mater., 9 (1997) 2354.

3. M. M. Collinson, A. R. Howells, Anal. Chem., 72 (2000) 702.

4. C. J. Brinker, G. C. Frye, A. J. Hurd, C. S. Ashley, Thin Solid Films, 201 (1991) 97.

5. M. M. Collinson, D. A. Higgins, R. Kommidi, D. Campbell-Rance, Anal. Chem., 80 (2008) 651.

6. M. M. Collinson, N. Moore, P. N. Deepa, M. Kanungo, Langmuir, 19 (2003) 7669.

7. I. Zhitomirsky, Advances in Colloid and Interface Science, 97 (2002) 279.

8. A. Walcarius, E. Sibottier, M. Etienne, J. Ghanbaja, Nat Mater, 6 (2007) 602.

9. M. M. Collinson, Acc. Chem. Res., 40 (2007) 777.

10. R. Shacham, D. Avnir, D. Mandler, Journal of Sol-Gel Science and Technology, 31 (2004) 329.

11. P. N. Deepa, M. Kanungo, G. Claycomb, P. M. A. Sherwood, M. M. Collinson, Anal. Chem., 75 (2003) 5399.

12. O. Nadzhafova, M. Etienne, A. Walcarius, Electrochemistry Communications, 9 (2007) 1189.

13. D. K. Yi, S. T. Selvan, S. S. Lee, G. C. Papaefthymiou, D. Kundaliya, J. Y. Ying, J. Am. Chem. Soc., 127 (2005) 4990.

14. J. Wang, P. V. A. Pamidi, D. S. Park, Electroanalysis, 9 (1997) 52.

15. K. Gong, M. Zhang, Y. Yan, L. Su, L. Mao, S. Xiong, Y. Chen, Anal. Chem., 76 (2004) 6500 .

16. S. Watcharotone, D. A. Dikin, S. Stankovich, R. Piner, I. Jung, G. H. B. Dommett, G. Evmenenko, S. E. Wu, S. F. Chen, C. P. Liu, S. T. Nguyen, R. S. Ruoff, Nano Lett., 7 (2007) 1888.

17. H. Schmidt, J Sol-Gel Sci Technol, 1 (1994) 217. 
18. S. H. Joo, J. Y. Park, C. K. Tsung, Y. Yamada, P. Yang, G. A. Somorjai, Nat Mater, 8 (2009) 126.

19. D. Salinas-Torres, F. Montilla, F. Huerta, E. Morallón, Electrochimica Acta, 56 (2011) 3620 .

20. A. Gamero-Quijano, F. Huerta, D. Salinas-Torres, E. Morallón, F. Montilla, Electrocatalysis, 4 (2013) 259.

21. R. L. McCreery, Chem. Rev., 108 (2008) 2646.

22. D. Salinas-Torres, F. Huerta, F. Montilla, E. Morallón, Electrochimica Acta, 56 (2011) 2464.

23. F. Montilla, M. A. Cotarelo, E. Morallon, J. Mater. Chem., 19 (2009) 305.

24. T. Dobbins, R. Chevious, Y. Lvov, 2011.

25. I. Pastor, A. Salinas-Castillo, R. Esquembre, R. Mallavia, C. R. Mateo, Biosensors and Bioelectronics, 25 (2010) 1526.

26. M. L. Ferrer, F. del Monte, D. Levy, Chem. Mater., 14 (2002) 3619.

27. R. Esquembre, J. A. Poveda, C. R. Mateo, J. Phys. Chem. B, 113 (2009) 7534.

28. R. Shacham, D. Avnir, D. Mandler, Adv. Mater., 11 (1999) 384.

29. G. Inzelt, M. Pineri, J. W. Schultze, M. A. Vorotyntsev, Electrochimica Acta, 45 (2000) 2403.

30. L. Duic', Z. Mandic', S. Kovac', Electrochimica Acta, 40 (1995) 1681.

31. R. S. Nicholson, Anal. Chem., 37 (1965) 1351. 